\title{
Selective recovery of cobalt(II) towards lithium(I) from chloride media by transport across polymer inclusion membrane with triisooctylamine
}

\author{
Beata Pospiech \\ Czestochowa University of Technology, Department of Chemistry, Armii Krajowej 19, 42-200 Częstochowa, Poland, \\ e-mail: b.pospiech@wip.pcz.pl
}

\begin{abstract}
In this work the selective transport of cobalt(II) and lithium(I) ions from aqueous chloride solutions through polymer inclusion membranes (PIMs) is presented. Triisooctylamine (TIOA) has been applied as the ion carrier in membrane. The effects of various parameters on the transport of $\mathrm{Co}(\mathrm{II})$ and $\mathrm{Li}(\mathrm{I})$ were studied. The obtained results show that $\mathrm{Co}(\mathrm{II})$ ions were effectively removed from source phase through PIM containing $32 \mathrm{wt} \%$ TIOA, 22 wt.\% CTA (cellulose triacetate) and 46 wt.\% ONPOE (o-nitrophenyl octyl ether) or ONPPE (o-nitrophenyl pentyl ether) into deionized water as the receiving phase. The results indicate that there is a possibility of polymer inclusion membranes application to recover $\mathrm{Co}(\mathrm{II})$ and $\mathrm{Li}(\mathrm{I})$ from aqueous chloride solutions.
\end{abstract}

Keywords: cobalt(II), lithium(I), triisooctylamine, polymer inclusion membrane (PIM), lithium-ion batteries (LIBs), solvent extraction.

\section{INTRODUCTION}

Cobalt and lithium have very important physicochemical properties and play a significant role in the industrial development. Lithium is the lightest metal, soft, silver-white, with a low melting point. Among the most significant properties of lithium we can find low viscosity and very low density, high specific heat as well as high thermal conductivity. Cobalt is a hard ferromagnetic metal. Its physicochemical properties are similar to those of iron and nickel. Cobalt is active chemically and forming many compounds. Cobalt is used in many alloys, such as superalloys, corrosion resistant alloys, high-speed steels, etc. ${ }^{1}$. A variety of applications of these metals, especially in the production of lithium ion batteries (LIBs), demands huge amounts of them. Cobalt is considered a strategic metal since it has many industrial and military uses. In 2010, the world resources of this metal were estimated at about 15 million tons and the world production was 88000 tons. Cobalt from purchased scrap represented an estimated $24 \%$ of cobalt consumption in 2010. The demand for cobalt will continue to increase owing to the development of countries such as China. Furthermore, this increase should accelerate with the expected increase of electric vehicle production as the total amount of cobalt in lithium batteries for an electric vehicle is not negligible, i.e. $81.4 \mathrm{~kg}$ of cobalt. Lithium use in batteries has expanded significantly in recent years because rechargeable lithium batteries have increasingly been used in portable electronic devices ${ }^{2}$. Lithium-ion batteries (LIBs) are used as electrochemical power sources in mobile telephones, laptops, video-cameras, etc. They are also likely to be chosen to provide power for electric automobiles in the future ${ }^{3,4}$. Total world production in 2009 and 2010 was about 18800 and 25 300 tons, respectively, and lithium prices have nearly tripled over the last 10 years ${ }^{2}$.

Natural sources of lithium are still relatively abundant whereas the sources of metals like cobalt, and rare earths are becoming more and more limited ${ }^{5}$. LIBs consist of heavy metals, organic chemicals and plastics, in the proportion of 5-20\% cobalt, 5-10\% nickel, 5-7\% lithium, $15 \%$ organic chemicals and $7 \%$ plastics, ${ }^{6}$. The exemplary composition of the mixed powder, after thermal treatment, is the following: 26.8 wt. $\%$ of $\mathrm{Co}, 3.3 \mathrm{wt} . \%$ of $\mathrm{Li}, 6.0$ wt.\% of $\mathrm{Al}, 1.2$ wt. \% of $\mathrm{Cu}, 3.8$ wt.\% of $\mathrm{Fe}$, 1.1 wt. $\%$ of $\mathrm{Mn}$ and 0.3 wt. $\%$ of $\mathrm{Ni}^{4}$. Beside cobalt and lithium, spent LIBs also contain many hazardous materials. Disposal of spent LIBs will result in environmental pollution. From the environmental viewpoint, the recycling of spent LIBs is highly desirable ${ }^{\mathbf{8}}$. LIBs should be recycled not only for environmental reasons, but also as an important secondary source of metals? The recycling of lithium-ion batteries (LIBs) is also very important because they can replace other types of batteries due to their light weight, high energy density and high performance.

Several investigations have been carried out to recover valuable metals from the waste cathodic active material $\left(\mathrm{LiCoO}_{2}\right)$ by hydrometallurgical processes. The hydrometallurgical processes are more favorable from an environmental viewpoint ${ }^{\mathbf{1 0}}$. The methods commonly include crushing, physical separation and acid leaching. After the leaching step, most of aluminum, iron and copper can be removed from the leach liquor by precipitation, ${ }^{911}$. The solvent extraction of cobalt and lithium from the leach liquor of LIBs has been reported by a number of researchers ${ }^{9-12}$. Although solvent extraction is frequently employed for the removal of metal ions from aqueous solutions, this technology requires a large amount of organic solvent, which is flammable, toxic or otherwise hazardous. An alternative separation technology of these metals is transport across liquid membranes. Swain et al. ${ }^{13}$ showed the comparison study using solvent extraction and membrane processes for the extraction of $\mathrm{Co}(\mathrm{II})$. For both process studies the suitable condition for extraction of $\mathrm{Co}(\mathrm{II})$ was found at feed solution $\mathrm{pH}$ 6.00. In the solvent extraction process the distribution coefficient depends upon equilibrium $\mathrm{pH}$ whereas in membrane process, the initial flux $\left(\mathrm{J}_{\mathrm{Co}(\mathrm{II})}\right)$ is independent of equilibrium $\mathrm{pH}$. For an efficient and effective extraction of $\mathrm{Co}(\mathrm{II})$ in solvent extraction a high value of distribution coefficient is necessary. So, to achieve a higher distribution coefficient, higher volume of the same extractant concentration or higher concentration of extractant is required. The membrane process has 
a comparatively better initial flux, which is a one of the advantages of this process over solvent extraction.

The separation of $\mathrm{Co}(\mathrm{II})$ and $\mathrm{Li}(\mathrm{I})$ ions from the simulated leach liquor of spent lithium ion batteries (LIBs) in transport process through SLMs with organophosphorous compounds was studied by several researches ${ }^{13-15}$. Sürücü et al. ${ }^{16}$ reported the separation of $\mathrm{Co}(\mathrm{II})$ from acidic media using SLM with basic reagents such as amines, e.g. Alamine 336 as mobile carrier. For SLMs, a major drawback is poor stability. Polymer inclusion membranes (PIMs) also belong to liquid membranes and have higher stability in a long-term separation process compared to SLM. The PIMs are formed by casting cellulose triacetate (CTA) from an organic solution containing ion carrier and a plasticizer, to form a thin film. Kozlowski et al. ${ }^{\mathbf{1 7}}$ studied a competitive transport of $\mathrm{Co}$ (II) from nitrate solutions through PIM containing organophosphorous acids. Recently, research involved the extraction of $\mathrm{Co}(\mathrm{II})$ from the solutions containing various concentrations of lithium chloride and hydrochloric acid using a poly(vinyl chloride) (PVC)-based polymer inclusion membrane with Aliquat 336 (quaternary ammonium compounds) as an ion carrier ${ }^{18,}{ }^{19}$.

The aim of the present work was the separation of $\mathrm{Co}(\mathrm{II})$ and $\mathrm{Li}(\mathrm{I})$ in the transport process through PIMs with triisooctylamine (TIOA) as the ion carrier. The simulated leach liquor of LIBs contained equimolar amounts of cobalt(II) and lithium(I) chlorides. The effect of various parameters including initial concentration of metal ions and $\mathrm{HCl}$ concentration in the source phase and composition of the membrane were studied.

\section{EXPERIMENTAL}

\section{Reagents}

Inorganic chemicals, i.e. $\mathrm{CoCl}_{2} \cdot 6 \mathrm{H}_{2} \mathrm{O}, \mathrm{LiCl}, \mathrm{HCl}$ were of analytical grade and were purchased from $\mathrm{POCh}$ (Gliwice, Poland). Aqueous solutions were prepared with deionized water. Organic reagents, i.e. triisooctylamine (TIOA, 98\%), cellulose triacetate (CTA), dichloromethane, $o$-nitrophenyl pentyl ether (ONPPE, 99\%), $o$-nitrophenyl octyl ether (ONPOE, 99\%) of analytical reagent grade were purchased from Fluka and used without further purification.

\section{Polymer inclusion membrane preparation}

The polymer membranes were prepared according to the procedure reported in the previous paper ${ }^{\mathbf{2 0}, 21}$. Solutions of cellulose triacetate (CTA), the ion carrier (TIOA), and the plasticizer - $o$-nitrophenyl octyl ether (ONPOE) or $o$-nitrophenyl pentyl ether (ONPPE) in dichloromethane were prepared. A portion of this solution was poured on a flat-bottom glass Petri dish $(7.0 \mathrm{~cm}$ diameter) which was kept on a leveled surface. The organic solvent was allowed to evaporate over a period of $12 \mathrm{~h}$. After evaporation of the solvent the obtained membrane was peeled off from the Petri dish by immersion in cold water. This membrane was soaked for $12 \mathrm{~h}$ in deionized water to achieve its homogeneity before use. The membrane contained $2.0 \mathrm{~cm}^{3}$ plasticizer $/ 1 \mathrm{~g}$ CTA. The thickness of the membrane was measured using the digital ultrameter (MG-401, Elmetron). The CTA concentration was optimized on the basis of preliminary experimental studies. The content of CTA must ensure a good mechanical strength of PIMs. The thickness of the resulting membranes was $65 \pm 2 \mu \mathrm{m}$.

\section{Transport studies}

To transport Co(II) and Li(I) across PIM, a membrane module was used, to which both aqueous phases were pumped with a peristaltic pump (PP1B-05A type, Zalimp, Poland) working at a speed of $100 \mathrm{~cm}^{3} \mathrm{~min}^{-1}$ from tanks containing source and receiving phases, respectively. Polymer inclusion membrane system with a sandwich type measurement module was used. The membrane was fixed in the measurement module - presented in Figure 1. The effective membrane area, which was exposed to both phases was $12.56 \mathrm{~cm}^{2}$. The volumes of source and receiving phases were $100 \mathrm{~cm}^{3}$, respectively. Both, the source and the receiving aqueous phases were stirred by a magnetic stirrer at $600 \mathrm{rpm}$. The permeation of metal ions was monitored by sampling the aqueous phases $\left(0.1 \mathrm{~cm}^{3}\right.$ each $)$ at different time intervals, which was analyzed by an atomic absorption spectrophotometer (Solaar 939, Unicam) to determine cobalt(II), lithium(I) concentrations. The source phase acidity was controlled by $\mathrm{pH}$ - meter (CX-731, Elmetron) with $\mathrm{pH}$ electrode (Hydromet, Poland). The $\mathrm{pH}$ of the source phase was kept constant. The PIM transport experiments were conducted at room temperature $\left(23-25^{\circ} \mathrm{C}\right)$. The kinetics of PIM transport process was described by a first-order reaction in metal ion concentration ${ }^{22}$ :

$\ln \left(\frac{c}{c_{i}}\right)=-k t$

were $c$ is the metal ion concentration $\left(\mathrm{mol} \cdot \mathrm{dm}^{-3}\right)$ in the source phase at some given time, $c_{i}$ is the initial metal ion concentration in the source phase, $k$ is the rate constant $\left(\mathrm{s}^{-1}\right)$, and $t$ is the time of transport $(s)$. To calculate the $k$ value, a plot of $\ln \left(c / c_{i}\right)$ versus time was prepared. A linear dependence of $\ln \left(c / c_{i}\right)$ in the source phase versus time was obtained and the permeability coefficient $(P)$ was calculated as follows:

$P=\frac{V}{A} k$

where $V$ is the volume of the aqueous source phase $\left(\mathrm{m}^{3}\right)$, and $A$ is an effective area of membrane $\left(\mathrm{m}^{2}\right)$. The initial flux $\left(J_{i}\right)$ was determined as:

$J_{i}=P \cdot c_{i}$

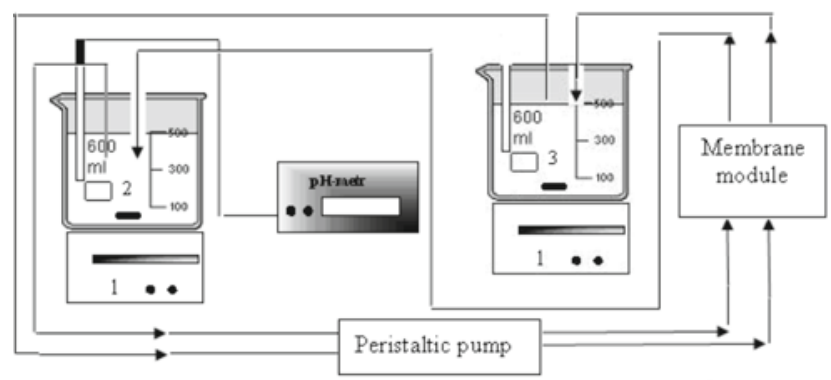

Figure 1. Diagram of the transport experiments through PIM: 1 - magnetic stirrer, 2 - source phase, 3 - receiving phase 
The selectivity coefficient $S$ for Co(II) over $\mathrm{Li}(\mathrm{I})$ was defined as the ratio of the initial fluxes for $\mathrm{Co}(\mathrm{II})$ and $\mathrm{Li}(\mathrm{I})$ ions, respectively:

$S=\frac{J_{i, C o(I)}}{J_{i, L i(I)}}$

The recovery factor $(R F)$ of metal ions from the source phase into receiving phase was calculated as:

$R F=\frac{c_{i}-c}{c_{i}} \cdot 100 \%$

were $c$ is the metal ion concentration $\left(\mathrm{mol} \cdot \mathrm{dm}^{-3}\right)$ in the source phase at some given time, $c_{i}$ is the initial metal ion concentration in the source phase.

\section{RESULTS AND DISCUSSION}

Effect of the initial concentration of $\mathrm{Co}(\mathrm{II})$ and $\mathrm{Li}(\mathrm{I})$ in the source phase

The influence of the initial concentration of the metal ions in the source phase on the kinetic parameters and selectivity of the transport process was investigated. The initial concentration of $\mathrm{Co}(\mathrm{II})$ and $\mathrm{Li}(\mathrm{I})$ was varied between $0.0010 \mathrm{~mol} \cdot \mathrm{dm}^{-3}$ to $0.10 \mathrm{~mol} \cdot \mathrm{dm}^{-3}$. The obtained results are summarized in Table 1 . When the metal ions concentration increases, the values of initial fluxes also increase. The results show that the initial flux for $\mathrm{Co}(\mathrm{II})$ increased sharply from $1.5 \mathrm{mmolm}^{-2} \mathrm{~s}^{-1}$ to $14.4 \mathrm{mmolm}^{-2} \mathrm{~s}^{-1}$ at the initial metal concentration of $0.010 \mathrm{~mol} \cdot \mathrm{dm}^{-3}$. The maximum initial flux of $\mathrm{Co}(\mathrm{II})$ and $\mathrm{Li}(\mathrm{I})$ was obtained when the concentration of these metal ions was $0.1 \mathrm{~mol} \cdot \mathrm{dm}^{-3}$. The selectivity coefficient $\left(\mathrm{S}_{\mathrm{Co}(\mathrm{II} / \mathrm{Li}(\mathrm{II}}\right)$ was the highest when the initial concentration of $\mathrm{Co}$ (II) and $\mathrm{Li}(\mathrm{I})$ was $0.010 \mathrm{~mol} \cdot \mathrm{dm}^{-3}$ and $0.070 \mathrm{~mol} \cdot \mathrm{dm}^{-3}$. Figure 2 shows changes of permeability coefficients depending on the metal ions concentration in the source phase. The permeability of $\mathrm{Co}(\mathrm{II})$ and $\mathrm{Li}(\mathrm{I})$ decreases with the increase of the initial metal ions concentration in the source phase. Similar results were obtained by Alguacil et al. ${ }^{15}$. They reported that apparently the permeation process is controlled by the diffusion of metal species in the lower range of cobalt concentration, whereas at the higher metal concentrations, the decrease in the $\mathrm{k}$ value (rate constant) may be attributable to two reasons.

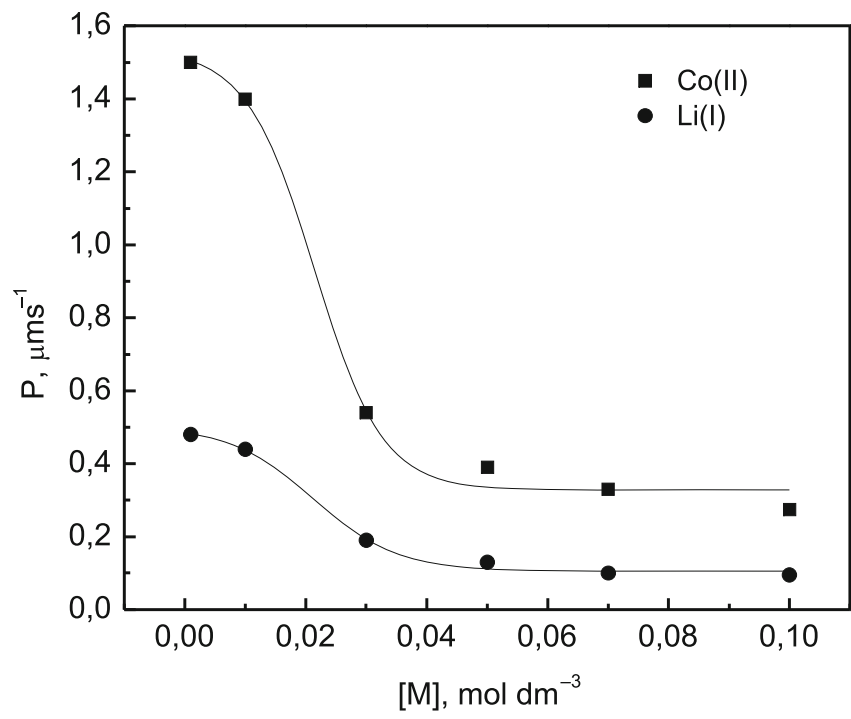

Figure 2. Effect of the initial $\mathrm{Co}(\mathrm{II})$ and $\mathrm{Li}(\mathrm{I})$ concentration on the permeability. Experimental conditions (see Table 1)

Firstly, due to a membrane saturation and, thus, a lower effective membrane area. Secondly, due to the saturation of the membrane micropores by the cobalt-carrier complexes, forming a layer on the membrane interface, which promotes the retention of the species responsible for cobalt transport on the side of feed membrane, and thus decreases of the value of the overall mass transfer coefficient.

\section{Effect of $\mathrm{HCl}$ concentration}

In order to investigate the influence of hydrochloric acid concentration in the source phase on the transport of $\mathrm{Co}(\mathrm{II})$ and $\mathrm{Li}(\mathrm{I})$, the experiments were performed at different concentration of this acid. The concentration of $\mathrm{HCl}$ varied from $1.0 \mathrm{~mol} \cdot \mathrm{dm}^{-3}$ to $4.0 \mathrm{~mol} \cdot \mathrm{dm}^{-3}$. Separation of $\mathrm{Co}(\mathrm{II})$ and $\mathrm{Li}(\mathrm{I})$ was carried out from the source phase containing $0.010 \mathrm{~mol} \cdot \mathrm{dm}^{-3}$ of each metal ions and deionized water as the receiving phase. The results are presented in Figure 3. The recovery factor (RF, \%) after $8 \mathrm{~h}$ for $\mathrm{Co}(\mathrm{II})$ increased from $28.1 \%$ to $45.5 \%$ with increasing the $\mathrm{HCl}$ concentration in the source phase. For $\mathrm{Li}(\mathrm{I})$ this dependence was the opposite, i.e. the recovery factor decreased from $9.3 \%$ to $3.2 \%$

Table 1. Kinetic parameters for $\mathrm{Co}(\mathrm{II})$ and $\mathrm{Li}(\mathrm{I})$ transport through PIM in depending on the metal ions concentration in the source phase. PIM: $2.0 \mathrm{~mol} \cdot \mathrm{dm}^{-3} \mathrm{TIOA}, 2.0 \mathrm{ONPOE} / 1 \mathrm{~g} \mathrm{CTA}$; the source phase: $[\mathrm{Co}(\mathrm{II})]=[\mathrm{Li}(\mathrm{I})]$, $\mathrm{pH}=6.5$; the receiving phase: $\mathrm{H}_{2} \mathrm{O}$

\begin{tabular}{|c|c|c|c|c|}
\hline Metal ions & $\begin{array}{c}\text { Concentration of metal } \\
\text { ions } \\
{[\mathrm{M}]} \\
\left(\mathrm{mol} \cdot \mathrm{dm}^{-3}\right)\end{array}$ & $\begin{array}{c}\text { Rate constant } \\
k \\
\left(h^{-1}\right)\end{array}$ & $\begin{array}{c}\text { Initial flux } \\
J_{o,} \\
\left(\mu m o / m^{-2} s^{-1}\right)\end{array}$ & $\begin{array}{l}\text { Selectivity coefficient, } \\
S_{\text {Co }(I I) /(I)}\end{array}$ \\
\hline $\mathrm{Co}(\mathrm{II})$ & \multirow{2}{*}{0.0010} & 0.042 & 1.50 & \multirow{2}{*}{3.1} \\
\hline $\mathrm{Li}(\mathrm{I})$ & & 0.014 & 0.48 & \\
\hline $\mathrm{Co}(\mathrm{II})$ & \multirow{2}{*}{0.010} & 0.041 & 14.4 & \multirow{2}{*}{3.3} \\
\hline $\mathrm{Li}(\mathrm{I})$ & & 0.012 & 4.40 & \\
\hline $\mathrm{Co}(\mathrm{II})$ & \multirow{2}{*}{0.030} & 0.015 & 16.2 & \multirow{2}{*}{2.8} \\
\hline $\mathrm{Li}(\mathrm{I})$ & & 0.0055 & 5.8 & \\
\hline $\mathrm{Co}(\mathrm{II})$ & \multirow{2}{*}{0.050} & 0.011 & 19.5 & \multirow{2}{*}{3.1} \\
\hline $\mathrm{Li}(\mathrm{I})$ & & 0.0036 & 6.3 & \\
\hline $\mathrm{Co}(\mathrm{II})$ & \multirow{2}{*}{0.070} & 0.0095 & 23.4 & \multirow{2}{*}{3.3} \\
\hline $\mathrm{Li}(\mathrm{I})$ & & 0.0029 & 7.1 & \\
\hline $\mathrm{Co}(\mathrm{II})$ & \multirow{2}{*}{0.10} & 0.008 & 27.5 & \multirow{2}{*}{2.9} \\
\hline $\mathrm{Li}(\mathrm{I})$ & & 0.003 & 9.50 & \\
\hline
\end{tabular}




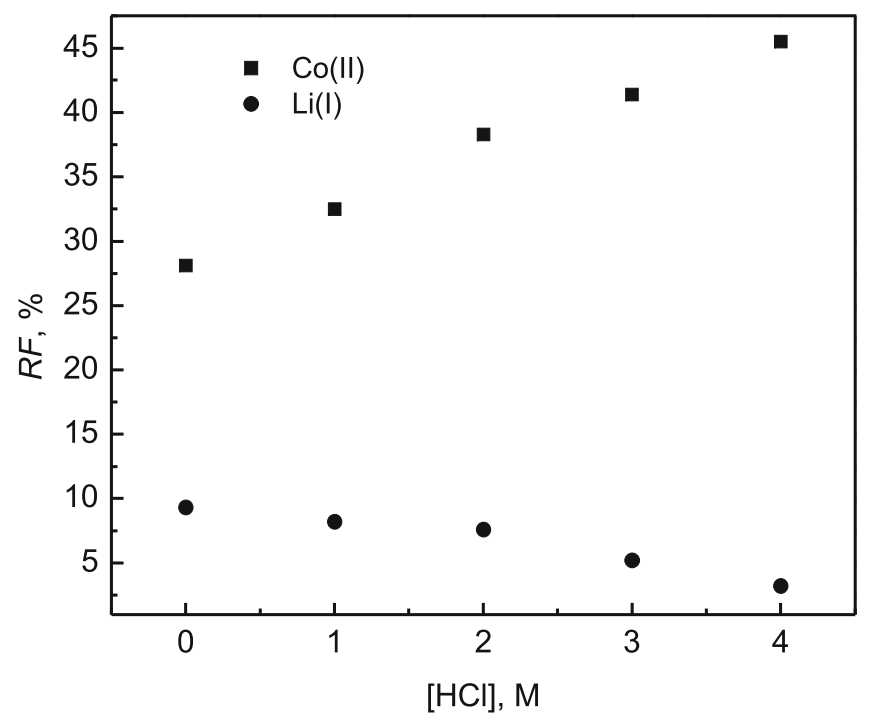

Figure 3. Effect of $\mathrm{HCl}$ concentration in the source phase on the recovery factor of $\mathrm{Co}(\mathrm{II})$ and $\mathrm{Li}(\mathrm{I})$ after 8 h. Experimental conditions: PIM: $2 \mathrm{~mol} \cdot \mathrm{dm}^{-3}$ TIOA, $2.0 \mathrm{~cm}^{3}$ ONPOE $/ 1 \mathrm{~g}$ CTA; the source phase: $0.010 \mathrm{~mol} \cdot \mathrm{dm}^{-3} \mathrm{Co}(\mathrm{II}), 0.010 \mathrm{~mol} \cdot \mathrm{dm}^{-3} \mathrm{Li}(\mathrm{I})$; the receiving phase: $\mathrm{H}_{2} \mathrm{O}$

with increasing the $\mathrm{HCl}$ concentration. The selectivity coefficient for $\mathrm{Co} / \mathrm{Li}$ increased with the increasing of $\mathrm{HCl}$ concentration in the source phase from 3.1 to 14.2. The increase of cobalt(II) recovery with increasing $\mathrm{HCl}$ concentration can be attributed to the fact that in chloride solutions $\mathrm{Co}$ (II) form stable anionic complexes of the type $\mathrm{CoCl}_{4}^{2-}$ or $\mathrm{CoCl}_{3}^{-23}$, in contrast to $\mathrm{Li}(\mathrm{I})$. TIOA (shown as $\mathrm{R}_{3} \mathrm{~N}$ ) in the membrane phase reacts with hydrochloric acid in the source phase $\mathrm{e}^{21,23}$ :

$\mathrm{R}_{3} \mathrm{~N}+\mathrm{H}^{+}+\mathrm{Cl}^{-} \rightarrow \mathrm{R}_{3} \mathrm{NH}^{+} \mathrm{Cl}^{-}$

In the source phase $\mathrm{CoCl}_{4}{ }^{2-}$ or $\mathrm{CoCl}_{3}{ }^{-}$ions exchange with $\mathrm{Cl}^{-}$of $\mathrm{R}_{3} \mathrm{NH}^{+} \mathrm{Cl}^{-}$in the membrane phase:

$\mathrm{CoCl}_{4}^{2-}+2 \mathrm{R}_{3} \mathrm{NH}^{+} \mathrm{Cl}^{-} \rightarrow\left(\mathrm{R}_{3} \mathrm{NH}\right)_{2} \mathrm{CoCl}_{4}{ }^{2-}+2 \mathrm{Cl}^{-}$

$\mathrm{CoCl}_{3}^{-}+\mathrm{R}_{3} \mathrm{NH}^{+} \mathrm{Cl}^{-} \rightarrow\left(\mathrm{R}_{3} \mathrm{NH}\right) \mathrm{CoCl}_{3}^{-}+\mathrm{Cl}^{-}$

The influence of the hydrochloric acid concentration on the recovery of $\mathrm{Co}$ (II) was also studied by Blitz-Raith et al. ${ }^{19}$ using the $40 \%$ Aliquat 336 chloride/PVC membrane composition. The percentage of $\mathrm{Co}$ (II) also increased steadily with increasing the $\mathrm{HCl}$ concentration from 1.0 to $7.0 \mathrm{~mol} \cdot \mathrm{dm}^{-3}$.

\section{Effect of the membrane composition on the transport of $\mathrm{Co}(\mathrm{II}) / \mathrm{Li}(\mathrm{I})$}

The PIMs contained polymer, ion carrier and plasticizer. The kind of the carrier and its concentration in the membrane play a significant role during the permeation of metal ions in transport processes across PIM. In this work the effect of TIOA concentration on the transport of $\mathrm{Co}(\mathrm{II})$ and $\mathrm{Li}(\mathrm{I})$ ions was investigated. The concentration of TIOA was varied from $0.5 \mathrm{~mol} \cdot \mathrm{dm}^{-3}$ to $2.0 \mathrm{~mol} \cdot \mathrm{dm}^{-3}$ (on volume of plasticizer). The plasticizer concentration was $2.0 \mathrm{~cm}^{3} / 1.0 \mathrm{~g}$ CTA. The transport of $\mathrm{Co}(\mathrm{II})$ was slow at low concentration of the ion carrier. Figure 4. shows dependence of the initial fluxes of the metal ions transported as the function of TIOA concentration for the PIMs with ONPOE and ONPPE as plasticizers, respectively. The plasticizers in polymer inclusion membranes improve their chemical and mechanical properties and stability of membrane. Frequently, $o$-nitrophenyl alkyl

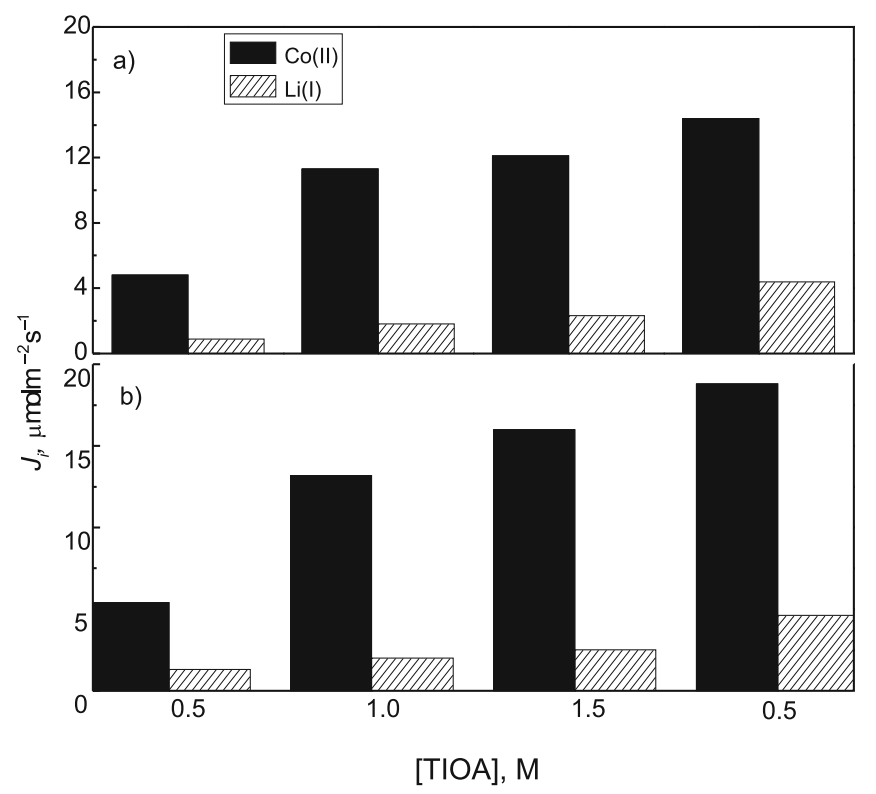

Figure 4. Effect of TIOA concentration in PIM on the initial flux $\left.{ }_{\mathrm{J} 0}\right)$ of $\mathrm{Co}(\mathrm{II})$ and $\mathrm{Li}(\mathrm{I})$ across PIM with different plasticizers a) ONPOE, b) ONPPE; the source phase: aqueous solution containing: $0.010 \mathrm{~mol} \cdot \mathrm{dm}^{-3}$ $\mathrm{Co}(\mathrm{II}), 0.010 \mathrm{~mol} \cdot \mathrm{dm}^{-3} \mathrm{Li}(\mathrm{I}), \mathrm{pH}=6.5$; the receiving phase: $\mathrm{H}_{2} \mathrm{O}$

ethers are used in the role of plasticizers in PIMs. The length of the alkyl group in $O$-nitrophenyl alkyl ethers is from $\mathrm{C}_{4} \mathrm{H}_{9}$ to $\mathrm{C}_{8} \mathrm{H}_{17}$. In order to study the influence of plasticizers type in PIM during the transport process of $\mathrm{Co}(\mathrm{II})$ and $\mathrm{Li}(\mathrm{I})$ ions, the PIMs were prepared by using the plasticizer having different a length of the alkyl chain. The plasticizers used in the preparation of PIM were: $o$-nitrophenyl pentyl ether (ONPPE) and $o$-nitrophenyl octyl ether (ONPOE). The membranes contained 22 wt. $\%$ CTA, 32 wt. $\%$ TIOA and 46 wt. $\%$ plasticizer. The plasticizers used in the investigation have similar viscosity and dielectric constant. The initial flux $\left(\mathrm{J}_{\mathrm{i}}\right)$ for $\mathrm{Co}(\mathrm{II})$ ions increases up to $2.0 \mathrm{~mol} \cdot \mathrm{dm}^{-3}$ with increasing carrier concentration for the PIMs containing ONPPE as plasticizer as well as for the PIM with ONPOE. The maximum transport of $\mathrm{Co}(\mathrm{II})$ ions was obtained by using the membrane containing $0.07 \mathrm{~g}$ of TIOA (2.0 mol $\cdot \mathrm{dm}^{-3}$ on volume of plasticizer $)$ and ONPPE as plasticizer.

The highest initial flux of $\mathrm{Co}(\mathrm{II})$ was $18.8 \mathrm{mmolm}^{-2} \mathrm{~s}^{1}$ for the PIM with ONPPE as plasticizer and $14.4 \mathrm{mmolm}^{-2} \mathrm{~s}^{-1}$ for the PIM with ONPOE as the plasticizer. Increase of carrier concentration in membrane phase caused a slight increase in $\mathrm{Li}(\mathrm{I})$ fluxes. Similar dependences were observed in the earlier investigation into separation of $\mathrm{Co}(\mathrm{II})$ and $\mathrm{Li}(\mathrm{I})$ by PIMs with a different type of ion carrier, i.e. Cyanex 301 (bis(2,4,4-trimethylpentyl)dithiophosphinic acid) ${ }^{24}$. The transport of $\mathrm{Co}(\mathrm{II})$ was slow at the low concentration of the ion carrier. The highest flux of cobalt(II) ions was obtained by transport through PIM containing 32 wt.\% Cyanex 301, 50 wt.\% ONPOE and 18 wt.\% CTA into $3.0 \mathrm{M}$ hydrochloric acid as the receiving phase. The obtained results show that the recovery factor of $\mathrm{Co}$ (II) ions after $12 \mathrm{~h}$ reached $98 \%$.

The plasticizers used in the investigation have similar viscosity and dielectric constant. The initial flux of Co(II) decreases little with an increase in $\mathrm{R}$ chain length of plasticizers. It can be observed that the removal of $\mathrm{Co}(\mathrm{II})$ 
ions from the feed phase was more effective when ONPPE is used as a plasticizer rather than ONPOE. Figure 5 presents the recovery factor values of the investigated metal ions from the source phase, determined after 24 $\mathrm{h}$ transport through PIM with TIOA and ONPPE as plasticizer. The recovery factor of $\mathrm{Co}(\mathrm{II})$ and $\mathrm{Li}(\mathrm{I})$ ions after $24 \mathrm{~h}$ was $74.5 \%$ and $5.3 \%$, respectively. This investigation confirms the earlier study conducted by other researchers. Previously, Kozlowski and Walkowiak ${ }^{17,25}$ suggested that only high polarity plasticizers can be preferentially used as solvents in PIMs. They also found the decrease in metal ions rate transport with increase in alkyl group length in a plasticizer.

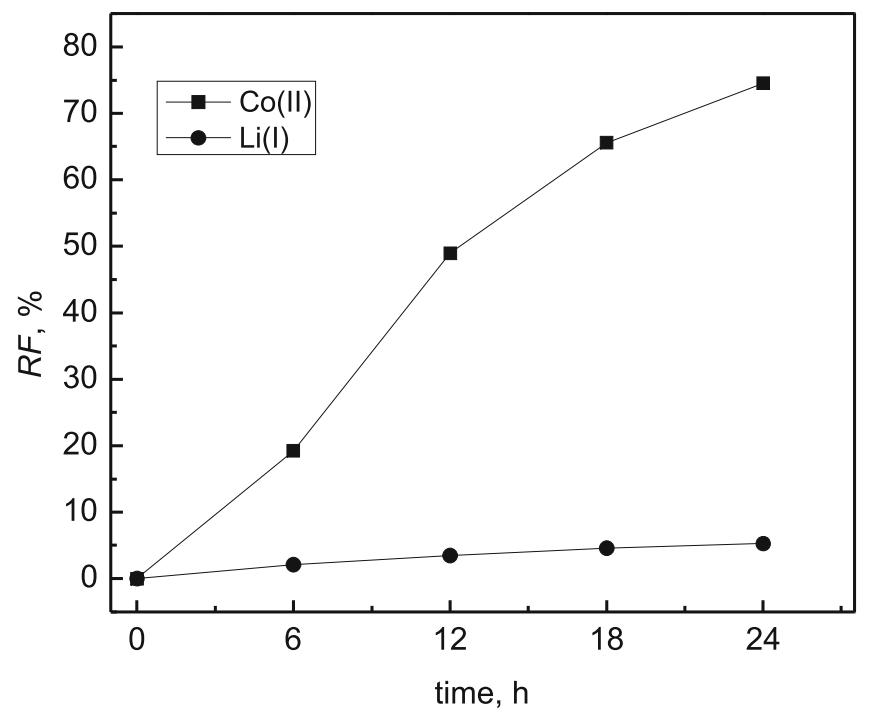

Figure 5. Recovery factor $(\%)$ of $\mathrm{Co}(\mathrm{II})$ and $\mathrm{Li}(\mathrm{I})$ in transport across PIM: 22 wt. $\%$ CTA, 32 wt.\% TIOA, 46 wt.\% ONPPE as plasticizer. Experimental conditions as in Figure 4

\section{CONCLUSIONS}

Polymer inclusion membranes with triisooctylamine as ion carrier provide an attractive alternative to conventional solvent extraction methods for the separation of cobalt(II) and lithium(I). The results show that cobalt(II) ions can be effectively recovered from aqueous chloride solutions containing lithium(I) in transport process across PIMs. The transport using triisooctylamine as the ion carrier showed high selectivity $\mathrm{Co}(\mathrm{II})>\mathrm{Li}(\mathrm{I})$. The transport process is affected by the initial concentration of metal ions and hydrochloric acid concentration in the source phase, as well as membrane composition, i.e. ion carrier concentration and the type of plasticizer. The obtained results show that the recovery factor of $\mathrm{Co}(\mathrm{II})$ and $\mathrm{Li}(\mathrm{I})$ using PIM with triisooctylamine, after $24 \mathrm{~h}$ reached $74.5 \%$ and $5.3 \%$, respectively. The highest selectivity coefficient in this process was 4.1 . Finally, the separation system presented in this paper can be useful for the separation of $\mathrm{Co}(\mathrm{II})$ and $\mathrm{Li}(\mathrm{I})$ from aqueous chloride solutions.

\section{LITERATURE CITED}

1. Bielanski, A. (2010). Inorganic Chemistry, PWN, Poland.

2. Chagnes, A. \& Pospiech, B. (2013). A brief review on hydrometallurgical technologies for recycling spent lithium-ion batteries, J. Chem. Technol. Biotechnol. 88 (7) 1191-1199. DOI: $10.1002 /$ jctb.4053.
3. Pospiech, B. (2012). Selective extraction of cobalt(II) and lithium(I) using phosphorous acids from leach liquor of spent lithium-ion batteries. Rudy i Metale Nieżelazne 6, 368-373.

4. Chen, L., Tang, X., Zhang, Y., Li, L., Zeng, Z. \& Zhang, Y. (2011). Process for the recovery of cobalt oxalate from lithium ion batteries. Hydrometallurgy 108, 80-86. DOI: 10.1016/j. hydromet.2011.04.013.

5. Väyrynen, A. \& Salminen, J. (2012). Lithium ion battery production. J. Chem. Thermodynamics 46, 80-85. DOI: 10.1016/j. jct.2011.09.005.

6. Lee, J.Ch. \& Pandey, B.D. (2012). Bio-processing of solid wastes and secondary resources for metal extraction - A review. Waste Management 32, 3018. DOI: 10.1016/j. wasman.2011.08.010.

7. Shin, S.M., Kim, N.H., Sohn, J.S., Yang, D.H. \& Kim, Y.H. (2005). Development of a metal recovery process from Li-ion battery wastes. Hydrometallurgy 79, 172-181. DOI: 10.1016/j. hydromet.2005.06.004.

8. Li, L., Ge, J., Wu, F., Chen, R., Chen, S. \& Wu, B. (2010). Recovery of cobalt and lithium from spent lithium-ion batteries using organic citric acid as leachant. J. Hazard. Mater. 176, 288-293. DOI: 10.1016/j.hazmat.2009.11.026.

9. Zhao, J.M., Shen, X.Y., Deng, F.L., Wang, F.C., Wu, Y. \& Liu, H.Z. (2011). Synergistic extraction and separation of valuable metals from waste cathodic material of lithium ion batteries using Cyanex 272. Sep. Purif. Technol. 78, 345-351. DOI: $10.1016 /$ j.seppur.2010.12.024.

10. Sun, L. \& Qiu, K. (2011). Vacuum pyrolysis and hydrometallurgical process for the recovery of valuable metals from spent lithium ion batteries. J. Hazard. Mater. 194, 378-384. DOI: 10.1016/j.jhazmat.2011.07.114.

11. Swain, B., Jeong, J., Lee, J., Lee, G.H. \& Sohn, J. (2007). Hydrometallurgical process for recovery of cobalt from waste cathodic active material generated during manufacturing of lithium ion batteries. J. Power Sources 167, 536-544. DOI: 10.1016/j.powsour.2007.02.046.

12. Suzuki, T., Nakamura, T., Inoue, Y., Niinae, M. \& Shibata, J. (2012). A hydrometallurgical process for the separation of aluminum, cobalt, copper and lithium in acidic sulfate media. Sep. Purif. Technol. 98, 396-401. DOI: org/10.1016/j. seppur.2012.06.034.

13. Swain, B., Jeong, J., Lee, J. \& Lee, G. (2007). Extraction of $\mathrm{Co}(\mathrm{II})$ by supported liquid membrane and solvent extraction using Cyanex 272 as an extractant: A comparison study. J. Membr. Sci. 288, 139-148. DOI: 10.1016/j.memsci.2006.11.012.

14. Swain, B., Jeong, J., Yoo, K. \& Lee, J. (2010). Synergistic separation of $\mathrm{Co}(\mathrm{II}) / \mathrm{Li}(\mathrm{I})$ for the recycling of LIB industry wastes by supported liquid membrane using Cyanex 272 and DP-8R. Hydrometallurgy 101, 20-27. DOI: 10.1016/j.hydromet.2009.11.012.

15. Alguacil, F.J., Alonso, M., Lopez, F.A., Lopez-Delgado, A. (2011). Active transport of cobalt(II) through a supported liquid membrane using the mixture DP8R and Acorga M5640 as extractant. Desalination 281, 221-225. DOI: 10.1016/j.desal.2011.07.064.

16. Sürücü, A., Eyüpoglu, V., Tutkun, O. (2010). Selective separation of cobalt and nickel by supported liquid membranes. Desalination 250, 1155-1156. DOI: 10.1016/j.desal.2009.09.131.

17. Kozłowski, C.A., Kozlowska, J., Pellowski, W. \& Walkowiak, W. (2006). Separation of cobalt-60, strontium-90, and cesium-137 radioisotopes by competitive transport across polymer inclusion membranes with organophosphorous acids. Desalination 198, 141-148. DOI: 10.1016/j.desal.2006.02.005.

18. Kagaya, S. Cattrall, R.W. \& Kolev, S.D. (2011). Solid-phase extraction of cobalt(II) from lithium chloride solutions using a poly(vinyl chloride)-based polymer inclusion membrane with Aliquat 336 as the carrier. Anal. Sci. 27, 653-7.

19. Blitz-Raith, A.H., Paimin, R., Cattral, R.W. \& Kolev, S.D. (2007). Separation of Co(II) from Ni(II) by solid phase extrac- 
tion into Aliquat 336 chloride immobilized in poly(vinyl chloride), Talanta 71, 419-423. DOI: 10.1016/j.talanta.2006.04.017.

20. Pospiech, B. (2012). Separation of silver(I) and copper(II) from aqueous solutions by transport through polymer inclusion membranes with Cyanex 471X. Sep. Sci. Technol. 47, 1413-1419. DOI: org/10.1080/01496395.2012.672521.

21. Pospiech, B. \& Walkowiak, W. (2007). Separation of copper(II), cobalt(II) and nickel(II) from chloride solutions by polymer inclusion membranes. Sep. Purif. Technol. 57, 461-465. DOI: 10.1016/j.tseppur.2006.07.005.

22. Danesi, R. (1984). Separation of metal species by supported liquid membranes. Sep. Sci. Technol. 19, 857-894.

23. Logeat, M., Mankowski, G., Molinier, J. \& Lenzi, M. (1982). Complete separation of copper and cobalt by solvent extraction with triisooctylamine, Hydrometallurgy 9, 105-113.

24. Pospiech, B. (2013). Hydrometallurgical recovery of cobalt(II) from acidic chloride solutions by transport through polymer inclusion membranes, Phys. Problems of Miner. Process., 49(2) 641-649.

25. Walkowiak, W., Bartsch, R.A., Kozlowski, C., Gega, J., Charewicz, W.A. \& Amiri-Eliasi, B. (2000). Separation and removal of metal ionic species by polymer inclusion membranes. J. Radioanal. Nucl. Chem. 246 (32) 643-650. 